\title{
Preference for flavoured cigar brands among youth, young adults and adults in the USA
}

\author{
Cristine D Delnevo, ${ }^{1}$ Daniel P Giovenco, ${ }^{1}$ Bridget K Ambrose, ${ }^{2}$ Catherine G Corey, ${ }^{2}$ \\ Kevin P Conway ${ }^{3}$
}

${ }^{1}$ Center for Tobacco

Surveillance \& Evaluation

Research, Rutgers-School of

Public Health, New Brunswick,

New Jersey, USA

${ }^{2}$ Center for Tobacco Products,

Food and Drug Administration, Rockville, Maryland, USA

${ }^{3}$ Division of Epidemiology,

Services, and Prevention

Research, National Institute on

Drug Abuse, Rockville,

Maryland, USA

Received 25 October 2013 Revised 18 March 2014 Accepted 20 March 2014

Published Online First

10 April 2014
CrossMark

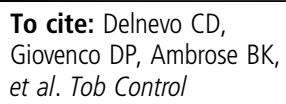

To cite: Delnevo CD, Giovenco DP, Ambrose BK, et al. Tob Control

2015;24:389-394.

\section{ABSTRACT}

Background While cigarette consumption in the USA continues to decline, cigar consumption has increased. Tobacco-trade publications suggest that flavoured cigars are driving the recent growth in cigar consumption. Limited survey data exist to explore flavoured cigar preferences among youth and adults.

Methods This study used the 2010-2011 National Survey on Drug Use and Health (NSDUH) and Nielsen market scanner data. The NSDUH sample consisted of 6678 past 30-day cigar smokers who reported smoking a usual brand of cigars. NSDUH contains a measure on usual cigar brand smoked and was merged with Nielsen data to estimate the per cent of each cigar brand's market share that is flavoured.

Results Multivariate analyses indicate that youth, young adults, females, blacks, cigarette smokers, blunt users and daily cigar smokers are significantly more likely to report a usual cigar brand that is flavoured. Preference for a usual brand that produces flavoured cigars decreases significantly with age.

Conclusions This study finds recent growth in flavoured cigar consumption and preference among youth and young adults for cigar brands that are flavoured. These findings underscore the need to expand monitoring of product attributes as well as individuallevel cigar use behaviours captured through population surveillance.

\section{INTRODUCTION}

While cigarette consumption in the USA continues to decline, consumption of cigars in the USA has significantly increased over the last two decades. ${ }^{12}$ Traditionally, cigar smoking in the USA was a behaviour primarily of older men, ${ }^{3}$ but increased marketing of cigars to youth, young adults and women ${ }^{3}$ has been linked to a rapid rise in cigar use in the mid-1990s. ${ }^{3-6}$ While some survey data suggest that the rise in cigar prevalence peaked by 1999-2000, ${ }^{2} 67$ US cigar consumption continued to increase from 3.4 to 6.2 billion sticks from 1993 to 2000 , and has more than tripled from 1993 to $2012 .{ }^{12}$ Indeed, nearly 14 billion cigars were consumed in the USA in $2012 .{ }^{1}$

The contemporary research literature clearly points to a variety of cigar products being popular among youth (12-17 year olds), young adults and minorities, particularly among black and urban youth. $^{8-11}$ The most recent National Survey on Drug Use and Health (NSDUH) data (2011) show elevated rates of past-month cigar use among young adult males, $18-25$ years of age, with the highest rates among white (18.5\%) and black (17.2\%) male young adults. Moreover, cigar use among young adults continues to increase. ${ }^{8} 1213$ While cigar use is generally less prevalent among youth than adults, rates among female youth often exceed those of their adult counterparts. ${ }^{13-15}$

While the increase in cigar use has been attributed to price differentials between cigarettes and cigars and the subsequent promotion of little cigars as cigarette substitutes, ${ }^{16}{ }^{17}$ flavouring may also be contributing to the popularity of cigars, particularly among young people. Flavouring masks the harshness and irritation of smoking, making these products easier to use and increasing their appeal among new users, most notably young people. ${ }^{18-23}$ The use of flavours (eg, cherry, chocolate) in cigars has been omnipresent for decades, and their appeal to both young people and females was noted by the tobacco industry more than 40 years ago. ${ }^{24} 25$ Tobacco-trade publications recently noted that cigar sales continue to grow and attribute this growth to increased demand for the already popular flavoured cigars in the context of the Family Smoking Prevention and Tobacco Control Act's (TCA) ban on characterising flavours (other than menthol and tobacco) in cigarettes. ${ }^{26} 27$

Although prior research shows that flavoured tobacco products appeal to youth, young adults, females and blacks, ${ }^{22-23} 2829$ detailed data on cigar use and preferences for flavouring on national surveys are sparse and infrequent. To date, only three published studies have examined flavoured cigars, with two being limited to adults, ${ }^{28} 29$ and a third limited to flavoured little cigar use among youth. ${ }^{30}$ Given the limited knowledge and data about flavoured cigar use, this study uses an ecological approach that draws on cigar brand-level characteristics based on national retail sales data, combined with data from the NSDUH, to examine use of flavoured cigar brands among youth, young adults and adults in the USA.

\section{METHODS}

\section{Data sources}

The NSDUH was identified for this study because it is the only national survey to date that addresses youth (12-17), young adults (18-25) and adults $(26+)$, and includes a question on usual cigar brand among past 30-day cigar smokers. Nielsen convenience store market scanner data were used to generate brand-specific flavoured cigar measures. Nielsen-derived brand data were merged with the 2010 and 2011 NSDUH data files based on usual cigar brand reported by respondent. Each data source is described below. 


\section{National Survey on Drug Use and Health}

We used data from the NSDUH, an annual survey that provides national drug and alcohol use estimates for the US civilian population aged 12 and older. The NSDUH is conducted in person via computer-assisted interviewing methods and employs a multistage probability sample to yield nationally representative findings. A detailed description of the survey design and sampling procedures is provided elsewhere ${ }^{13}$; specifics relevant to this analysis are found below. Because of our interest in current cigar users, we pooled data from two recently completed years (2010 and 2011) for this study. The 2010 and 2011 NSDUH public access dataset contains a sample of 55435 individual records. However, since our focus was on cigar brand, our sample was limited to the 6678 individuals who reported smoking cigars in the 30 days preceding the survey and reported a usual cigar brand. The demographic breakdown of the sample is found in table 1.

\section{Nielsen market scanner data}

Details on cigar flavouring by brand were extracted from Nielsen's Convenience Track system, which tracks sales data from a national sample of convenience stores through a combination of in-store retail scanner equipment (ie, barcode readers), as well as audits of sales in stores without scanner equipment. Nielsen's convenience store sample is representative of all convenience store types and includes chain stores, non-chain and independent convenience stores, as well as convenience stores found in gas stations. Using a proprietary mechanism, Nielsen applies sample weights to scanned retailer data before reporting. Nielsen reports sales data information (ie, sales units and dollars) for each cigar product by Universal Product Code (UPC). For the years of data examined, there were over 3500 unique cigar UPCs listed. Each UPC has a description that highlights specific attributes, such as flavour, which were coded using previously used procedures. ${ }^{31}$ When the presence of flavour was not clear from the description provided (a minority of cases), information about the products was sought online. Menthol was considered a flavour in this analysis. In addition,

Table 1 Prevalence and frequency of past month cigar smoking, 2010-2011 National Survey on Drug Use and Health

\begin{tabular}{|c|c|c|}
\hline & $\begin{array}{l}\text { Prevalence of past } \\
\text { month cigar smoking } \\
\%(95 \% \mathrm{Cl})\end{array}$ & $\begin{array}{l}\text { No. of past month cigar } \\
\text { smokers reporting usual } \\
\text { brand (unweighted)* }\end{array}$ \\
\hline \multicolumn{3}{|l|}{ Gender } \\
\hline Male & 8.4 (8.0 to 8.8 ) & 4955 \\
\hline Female & 2.0 (1.9 to 2.2$)$ & 1723 \\
\hline \multicolumn{3}{|l|}{ Race } \\
\hline White & 5.1 (4.9 to 5.4 ) & 4328 \\
\hline Black & $7.4(6.8$ to 8.1$)$ & 1102 \\
\hline Hispanic & 4.1 (3.6 to 4.6 ) & 761 \\
\hline Other & $3.2(2.6$ to 3.9$)$ & 487 \\
\hline \multicolumn{3}{|l|}{ Age (years) } \\
\hline $12-17$ & 3.3 (3.1 to 3.6 ) & 1224 \\
\hline $18-25$ & 11.1 (10.6 to 11.7$)$ & 3886 \\
\hline $26-34$ & 7.1 (6.5 to 7.7$)$ & 670 \\
\hline 35 or older & 3.6 (3.3 to 3.9$)$ & 898 \\
\hline Total & 5.1 (4.9 to 5.3$)$ & 6678 \\
\hline
\end{tabular}

we sought information online to classify brands as 'premium', which we defined as brands that produce large, hand-rolled cigars (ie, not machine-made). To calculate flavoured market share for each brand, we divided each brand's flavoured dollar sales by their total dollar sales. Dollar sales instead of unit sales were used in this study to account for the variation of unit packaging (eg, single stick and five pack each considered a 'unit'), although both are reported when describing the cigar market overall. We considered using sticks to calculate market share, but since little cigars are typically sold in packs of 20, their market share then drives the analysis and heavily inflates product characteristics associated with little cigars, even though they constitute a small proportion of unit sales.

\section{Variables and data analysis}

Two outcome variables were created based on the Nielsen data for the respective NSDUH year (2010 and 2011) and merged with NSDUH participant records based on usual cigar brand reported. First, we created a dichotomous variable that indicated whether or not the respondent's usual cigar brand sells flavoured products for each respective year. Second, we created a continuous variable that reflects the flavoured market share (\%) of the respondent's usual cigar brand for each respective year. While our primary focus was on demographic patterns of flavoured cigar use (ie, age, gender and race/ethnicity), we also considered whether cigarette smoking in the past 30 days, blunt use in the past 30 days, defined as taking tobacco out of a cigar and replacing it with marijuana, and frequency of cigar use in the past 30 days were associated with use of a flavoured cigar brand.

The dataset was weighted for the varying probability of selection, and statistical analyses were performed using SUDAAN V.11 (RTI, 2012), which corrects for the complex sample design. Prevalence estimates for our two outcome variables, with 95\% CIs, are presented for descriptive analyses. Logistic regression was used to model preference for a brand that is flavoured (brand includes flavours/brand does not include flavours), and multiple linear regression was used to model the per cent flavoured market share of the respondent's preferred cigar brand.

\section{RESULTS}

As shown in table 2, cigar dollar and unit sales in convenience stores increased by $30 \%$ and $21 \%$, respectively, between 2008 and 2011. Flavoured cigars drove growth during this period and were responsible for $75 \%$ of the total increase in sales. Indeed, flavoured cigar dollar and unit sales outpaced overall sales and increased 53\% and 39\%, respectively, and by 2011 represented almost half of the total cigar dollar sales. Although certain flavour groups (eg, wine and sweet/candy) nearly doubled their dollar sales during this period, diverse packaging styles and brands with largely flavoured market shares also contributed to the increase in flavoured cigar sales. For example, White Owl, whose products were $85.4 \%$ flavoured in 2011, jumped from the fifth to the third best-selling cigar brand in convenience stores and nearly doubled their total dollar sales. Other brands that offer mostly flavoured products, like Garcia y Vega, Santa Fe, Djarum (clove cigars) and Zig Zag, also reported sales growth and market share increases. Flavoured cigar market share also varies considerably by packaging, with the inexpensive single stick and two/three packs much more likely to be flavoured.

Among current cigar smokers reporting a usual brand in the NSDUH, Black \& Mild (31.3\%) was the most popular, followed by Swisher Sweets (16.7\%), Cohiba (4.6\%), Dutch Masters 
Table 2 Characteristics of cigars sold in US convenience stores: 2008 and 2011 Nielsen Scantrak

\begin{tabular}{|c|c|c|c|c|c|c|c|c|}
\hline & \multicolumn{4}{|l|}{2008} & \multicolumn{4}{|l|}{2011} \\
\hline & $\begin{array}{l}\text { Unit } \\
\text { (in millions) }\end{array}$ & $\$$ (in millions) & $\begin{array}{l}\text { Market } \\
\text { Share (\%) }\end{array}$ & $\%$ flavoured $(\%)$ & $\begin{array}{l}\text { Unit } \\
\text { (in millions) }\end{array}$ & \$ (in millions) & $\begin{array}{l}\text { Market } \\
\text { share (\%) }\end{array}$ & $\%$ flavoured (\%) \\
\hline Total cigar sales & 994.2 & 1742.23 & & & 1200.70 & 2261.00 & & \\
\hline Flavoured & 471.9 & 729.66 & 41.9 & & 655.7 & 1118.70 & 49.5 & \\
\hline \multicolumn{9}{|l|}{ Among flavoured* } \\
\hline Mint/menthol & 12.6 & 19.64 & 2.7 & $\mathrm{n} / \mathrm{a}$ & 17.6 & 37.50 & 3.4 & $\mathrm{n} / \mathrm{a}$ \\
\hline Wine & 86.8 & 110.12 & 15.1 & & 116.5 & 204.70 & 18.3 & \\
\hline Fruit & 300.1 & 450.50 & 61.7 & & 366.6 & 591.70 & 52.9 & \\
\hline Sweet & 53.9 & 111.68 & 15.3 & & 129.7 & 226.50 & 20.3 & \\
\hline Liquor/cocktail & 7.5 & 17.55 & 2.4 & & 4.2 & 12.40 & 1.1 & \\
\hline Other & 11 & 20.27 & 2.8 & & 21.1 & 45.80 & 4.1 & \\
\hline \multicolumn{9}{|l|}{ Brands } \\
\hline Black \& Mild & 227.9 & 390.42 & 22.4 & 31.3 & 347.1 & 642.20 & 28.4 & 36.8 \\
\hline Swisher Sweets & 291 & 532.93 & 30.6 & 37.4 & 315.3 & 603.90 & 26.7 & 38.1 \\
\hline White Owl & 88.4 & 106.56 & 6.1 & 78.9 & 140.7 & 208.50 & 9.2 & 85.4 \\
\hline Dutch Masters & 108.7 & 188.58 & 10.8 & 28.9 & 111 & 198.70 & 8.8 & 45.0 \\
\hline Phillies & 103.6 & 145.64 & 8.4 & 61.9 & 48.5 & 90.10 & 4.0 & 71.7 \\
\hline Garcia Y Vega & 35.3 & 64.57 & 3.7 & 55.3 & 51.4 & 88.40 & 3.9 & 66.3 \\
\hline Backwoods & 14.1 & 75.95 & 4.4 & 38.0 & 16 & 76.20 & 3.4 & 79.4 \\
\hline Cheyenne & 12.3 & 14.73 & 0.8 & 60.3 & 22.9 & 50.90 & 2.2 & 62.6 \\
\hline Prime Time & 22.3 & 31.97 & 1.8 & 98.2 & 19.4 & 35.60 & 1.6 & 98.6 \\
\hline Santa Fe & 7.8 & 9.61 & 0.6 & 56.4 & 11.6 & 29.20 & 1.3 & 50.6 \\
\hline Hav-A-Tampa & 12 & 34.58 & 2.0 & 4.8 & 6.4 & 25.50 & 1.1 & 2.1 \\
\hline Djarum & $\mathrm{n} / \mathrm{a}$ & $\mathrm{n} / \mathrm{a}$ & $\mathrm{n} / \mathrm{a}$ & $\mathrm{n} / \mathrm{a}$ & 4.2 & 22.50 & 1.0 & 100.0 \\
\hline Zig Zag & 0 & $\$ 0.00$ & 0.0 & 0.0 & 17.2 & 18.40 & 0.8 & 76.3 \\
\hline Blackstone & 2.1 & 6.79 & 0.4 & 98.1 & 2.9 & 10.80 & 0.5 & 100.0 \\
\hline Antonio y Cleopatra & 3.1 & 14.21 & 0.8 & 0.2 & 1.6 & 10.30 & 0.5 & 0.1 \\
\hline Al Capone & 2.4 & 8.25 & 0.5 & 99.9 & 2.4 & 7.70 & 0.3 & 100.0 \\
\hline Macanudo (P)† & 0.2 & 1.46 & 0.1 & 0.0 & 0.2 & 2.10 & 0.1 & 0.0 \\
\hline Romeo y Julieta (P) & 0.1 & 0.42 & 0.0 & 0.0 & 0.1 & 1.00 & 0.0 & 0.0 \\
\hline Punch (P) & $\mathrm{n} / \mathrm{a}$ & $\mathrm{n} / \mathrm{a}$ & $\mathrm{n} / \mathrm{a}$ & $\mathrm{n} / \mathrm{a}$ & 0 & 0.20 & 0.0 & 0.0 \\
\hline Partagas (P) & 0 & 0.10 & 0.0 & 0.0 & 0 & 0.20 & 0.0 & 0.0 \\
\hline Cohiba (P) & 0 & 0.10 & 0.0 & 0.0 & 0 & 0.10 & 0.0 & 0.0 \\
\hline Montecristo (P) & 0 & 0.21 & 0.0 & 0.0 & 0 & 0.10 & 0.0 & 0.0 \\
\hline Acid (P) & 0 & 0.00 & 0.0 & 0.0 & 0 & 0.10 & 0.0 & 20.5 \\
\hline Other & 62.9 & 115.13 & 6.6 & 45.6 & 81.8 & 138.50 & 6.2 & 45.0 \\
\hline \multicolumn{9}{|l|}{ Packaging } \\
\hline Single stick & 633.9 & 577.43 & 33.1 & 52.6 & 773.2 & 844.80 & 37.4 & 55.3 \\
\hline 2 or 3 pack & 9.3 & 12.64 & 0.7 & 95.8 & 146.8 & 249.10 & 11.0 & 70.9 \\
\hline 5 pack & 228.8 & 742.19 & 42.6 & 34.7 & 160.5 & 761.30 & 33.7 & 39.6 \\
\hline 20 pack (LC) & 71.3 & 147.10 & 8.4 & 40.7 & 90 & 236.50 & 10.5 & 43.9 \\
\hline Other & 50.9 & 262.76 & 15.1 & 36.6 & 30.3 & 169.40 & 7.5 & 40.9 \\
\hline
\end{tabular}

Market share calculated based on dollars; standardised to 2011 dollars to adjust for inflation.

* Sweet includes flavours such as chocolate, vanilla and honey; liquor/cocktail includes flavours such as Strawberry Daquiri, Mojito, Rum.

$\dagger(P)$ denotes a premium cigar brand.

(4.5\%), Romeo y Julieta (4.1\%), Montecristo (4.0\%), White Owl (3.9\%), Backwoods (3.6\%) and Phillies (3.4\%) (see table 3). The premium brands Cohiba, Romeo y Julieta, Montecristo, Arturo Fuente, Macanudos, Punch, Partagas and Acid were preferred by a collective $20.9 \%$ of cigar smokers, while $3.0 \%$ preferred another premium brand. As shown in table 3, preference for certain brands varied significantly by age group. Preference for several inexpensive mass market, machine-made produced brands, including Black \& Mild, Swisher Sweets and White Owl, decreased with age, while preference for premium cigar brands, as well as Garcia y Vega and Backwoods, increased with age. For example, $50.5 \%$ and $3.8 \%$ of 12 - to 17 -year-old cigar smokers preferred Black \& Mild brand and premium brand cigars, respectively, whereas $18.0 \%$ and $35.0 \%$ of cigar smokers ages 35 and over prefer Black \& Mild and premium brand cigars, respectively.

Overall, $75.1 \%$ of cigar smokers reported a usual cigar brand that offers flavoured varieties; this varied significantly by gender, age, race/ethnicity, current cigarette use, current blunt use and past month cigar use frequency (see table 4). Cigar brands that offer flavoured varieties were preferred by $94.0 \%$ of females compared with $70.6 \%$ of males; $94.4 \%$ of black cigar smokers compared with $70.0 \%$ and $74.4 \%$ of whites and Hispanics, respectively; $84.7 \%$ of current cigarette smokers compared with $64.4 \%$ of those who do not smoke cigarettes; $94.5 \%$ of current blunt users compared with $70.4 \%$ of non- 
Table 3 Preferred cigar brand by age group, 2010-2011 National Survey on Drug Use and Health

\begin{tabular}{|c|c|c|c|c|c|}
\hline & $\begin{array}{c}12-17 \\
\%(95 \% \mathrm{Cl})\end{array}$ & $\begin{array}{l}18-25 \\
\%(95 \% \mathrm{Cl})\end{array}$ & $\begin{array}{l}26-34 \\
\%(95 \% \mathrm{Cl})\end{array}$ & $\begin{array}{l}35+ \\
\%(95 \% \mathrm{Cl})\end{array}$ & $\begin{array}{l}\text { Overall } \\
\%(95 \% \mathrm{CI})\end{array}$ \\
\hline Black \& Mild & 50.5 (46.1 to 54.8$)$ & 42.1 (39.6 to 44.6 ) & 34.7 (30.3 to 39.5$)$ & 18.0 (15.1 to 21.3$)$ & 31.3 (29.5 to 33.1$)$ \\
\hline Swisher Sweets & 21.0 (17.4 to 25.0$)$ & 19.4 (17.6 to 21.3 ) & 13.8 (10.6 to 17.8$)$ & $15.5(12.5$ to 19.0$)$ & 16.7 (15.2 to 18.4$)$ \\
\hline Cohiba $(P)^{*}$ & 0.2 (0.1 to 0.6$)$ & $2.0(1.6$ to 2.5$)$ & 8.8 (6.0 to 12.6$)$ & 5.3 (3.8 to 7.5$)$ & 4.6 (3.8 to 5.6 ) \\
\hline Dutch Masters & 5.1 (3.5 to 7.4 ) & 5.5 (4.6 to 6.7$)$ & 3.6 (1.9 to 6.7$)$ & 3.9 (2.3 to 6.6$)$ & 4.5 (3.5 to 5.7$)$ \\
\hline Romeo y Julieta (P) & $0.5(0.2$ to 1.5$)$ & 3.5 (2.7 to 4.5$)$ & 3.7 (2.1 to 6.4$)$ & 5.4 (3.8 to 7.5 ) & 4.1 (3.3 to 5.0$)$ \\
\hline Montecristo (P) & 1.5 (0.9 to 2.6$)$ & 1.2 (0.8 to 2.0$)$ & $4.4(2.2$ to 8.8$)$ & $6.4(3.9$ to 10.4$)$ & $4.0(2.7$ to 5.9$)$ \\
\hline White Owl & $5.9(4.4$ to 7.9$)$ & 5.4 (4.5 to 6.4$)$ & 3.9 (2.3 to 6.5$)$ & 2.5 (1.5 to 4.1$)$ & 3.9 (3.3 to 4.7$)$ \\
\hline Backwoods & $1.7(1.0$ to 3.0$)$ & 2.7 (2.2 to 3.5$)$ & 3.3 (1.9 to 5.6$)$ & 4.8 (3.1 to 7.3 ) & 3.6 (2.7 to 4.8$)$ \\
\hline Phillies & 3.9 (2.7 to 5.6$)$ & 4.4 (3.5 to 5.7$)$ & 4.0 (2.4 to 6.4$)$ & 2.2 (1.4 to 3.6) & 3.4 (2.7 to 4.2$)$ \\
\hline Arturo Fuente $(\mathrm{P})$ & $0.6(0.2$ to 1.9$)$ & 1.0 (0.6 to 1.6$)$ & 1.0 (0.5 to 2.2 ) & 5.5 (3.6 to 8.4$)$ & 2.8 (2.0 to 3.9$)$ \\
\hline Garcia y Vega & $0.6(0.3$ to 1.4$)$ & 1.3 (0.9 to 1.8$)$ & $1.7(0.9$ to 3.0$)$ & 4.6 (3.1 to 6.8 ) & 2.7 (2.0 to 3.6) \\
\hline Macanudos (P) & & $0.8(0.4$ to 1.5$)$ & 2.8 (1.7 to 4.5$)$ & 3.5 (2.2 to 5.6$)$ & 2.3 (1.6 to 3.2 ) \\
\hline Al Capone & $1.5(0.8$ to 2.7$)$ & 2.2 (1.6 to 3.0$)$ & $1.1(0.5$ to 2.3$)$ & 1.9 (1.0 to 3.4$)$ & 1.8 (1.4 to 2.4$)$ \\
\hline Punch (P) & $0.4(0.1$ to 1.3$)$ & $0.3(0.1$ to 0.7$)$ & 1.4 (0.6 to 3.3 ) & $2.5(1.5$ to 4.1$)$ & 1.4 (1.0 to 2.2 ) \\
\hline Partagas (P) & 0.1 (0.0 to 0.6$)$ & 0.2 (0.0 to 0.6$)$ & 0.5 (0.2 to 1.4$)$ & 2.2 (1.1 to 4.4$)$ & 1.1 (0.6 to 2.0 ) \\
\hline Cheyenne little cigars & $0.9(0.5$ to 1.6$)$ & $0.6(0.3$ to 1.0$)$ & 0.8 (0.3 to 2.0$)$ & $1.5(0.8$ to 2.7$)$ & 1.0 (0.7 to 1.5$)$ \\
\hline Blackstone & $0.3(0.2$ to 0.5$)$ & $0.4(0.2$ to 0.7$)$ & $0.5(0.1$ to 2.3$)$ & 1.4 (0.6 to 3.2$)$ & 0.8 (0.4 to 1.5$)$ \\
\hline Antonio y Cleopatra & 0.5 (0.2 to 1.7$)$ & 0.1 (0.1 to 0.3$)$ & 1.1 (0.4 to 3.5$)$ & 1.1 (0.5 to 2.5$)$ & 0.8 (0.4 to 1.4$)$ \\
\hline Prime Time & $1.4(0.7$ to 2.7$)$ & 1.1 (0.7 to 1.6$)$ & 0.9 (0.4 to 2.0$)$ & $0.2(0.1$ to 0.6$)$ & 0.7 (0.5 to 1.0$)$ \\
\hline Acid (P) & 0.1 (0.0 to 0.6$)$ & $1.2(0.7$ to 2.3$)$ & 0.7 (0.3 to 1.6$)$ & 0.2 (0.1 to 0.9$)$ & $0.6(0.4$ to 1.0$)$ \\
\hline Other brand, premium & 0.5 (0.1 to 1.9$)$ & 1.9 (1.4 to 2.6$)$ & 3.4 (2.0 to 5.5$)$ & 4.2 (2.7 to 6.4$)$ & 3.0 (2.3 to 4.0$)$ \\
\hline Other brand, not premium & 2.8 (1.7 to 4.3$)$ & 2.7 (2.1 to 3.4$)$ & 3.8 (2.2 to 6.6$)$ & $7.0(4.8$ to 10.0$)$ & 4.7 (3.6 to 6.1$)$ \\
\hline
\end{tabular}

*(P) denotes a premium cigar brand.

blunt users; and $90.8 \%$ of daily cigar smokers compared with $70.3 \%$ of cigar smokers who smoked occasionally (ie, less than 5 days in past 30). Additionally, reporting a usual brand that makes flavoured cigars decreased significantly with age, as $95.1 \%$ of $12-17$ year olds reported a usual brand that makes flavoured cigars compared with $63.2 \%$ of cigar smokers aged 35 and older. The extent to which usual brands were flavoured followed similar trends. For example, females reported usual cigar brands for which a higher proportion of products are flavoured (46.4\%) more often than males (35.8\%). Having a usual brand with a largely flavoured market share was highest among 1217 year olds and decreased with age. Likewise, the usual brands of black smokers (43.9\%) had a higher flavoured market share than those brands reported by whites (36.3\%) and Hispanics (36.7\%). Current cigarette smokers, current blunt users and daily cigar smokers also reported smoking a usual brand with a substantially flavoured market share.

Table 4 also summarises the results of the multivariate analyses and isolates the association of preference for flavoured cigars with main variables of interest (ie, gender, age, race/ethnicity) while accounting for all covariates (ie, cigarette use, blunt use and cigar frequency) in the models. All variables were significantly associated with reporting a usual brand that is flavoured and the extent to which the usual brand is flavoured (ie, the proportion of its sales that are flavoured). In particular, strong positive associations were noted for females, blacks, youth and young adults, blunt use and daily cigar use in both models.

\section{CONCLUSION}

To our knowledge, this is the first study to assess preference for flavoured cigar brands among youth, young adults and adults in a single study. Consistent with the limited research literature on flavoured tobacco products, 22232829 our findings highlight that there is a clear preference for cigar brands that produce flavoured varieties among youth, young adult, female and black cigar smokers. It is worth noting that preference for menthol cigarettes has also been noted among these same demographic groups. $^{32}$ This is not surprising given that menthol is a flavour that masks the harshness of tobacco. Moreover, this study also indicates that a preference for flavoured cigars is associated with current cigarette smoking, current blunt use and frequency of cigar smoking. These findings require further discussion. First, that current cigarette smoking is associated with preference for flavoured cigar brands is not surprising. Cigarette smokers were more likely to prefer filtered cigar brands (eg, Cheyenne, Santa $\mathrm{Fe}$ ) and cigar brands that include filtered cigars in their product line (eg, Swisher Sweets, Black \& Mild) than non-cigarette smokers. These brands have a notable flavoured market share. Second, as previously noted, flavoured cigars are popular for blunt smoking ${ }^{33}$ as one of the benefits of flavouring is that it masks the smell of the burning marijuana. ${ }^{33}$ This is also evident in the widespread use of flavourings in 'blunt wrappers', the rolling papers sold in sealed packages typically used to roll blunts of marijuana. ${ }^{34}$ Third, while cigar use is often referred to as an 'occasional' behaviour ${ }^{3}$ and may in fact be the case for smoking premium cigars, cigar use is frequent for some cigar smokers, and daily cigar smokers were more likely to prefer brands that use flavours.

The strengths of the study include a large and representative national sample that includes both young people and adults. In addition, we enhanced the utility of the NSDUH data by linking to brand-specific UPC sales to characterise the cigar market. The UPC scanner data allowed us to innovatively address a major limitation of our tobacco surveillance systems by allowing us to assess patterns in tobacco consumption beyond basic prevalence (ie, who uses the products and how often). However, a few study limitations should be noted. First, few brands were 100\% 
Table 4 Descriptive and multivariate analyses* of the associations with flavoured cigar brand use, 2010-2011 National Survey on Drug Use and Health

\begin{tabular}{|c|c|c|c|c|c|c|c|c|}
\hline & \multicolumn{4}{|c|}{ Usual brand makes flavoured cigars } & \multicolumn{4}{|c|}{ Flavoured market share among usual brand } \\
\hline & \multirow[b]{2}{*}{$\%$} & \multirow[b]{2}{*}{$95 \% \mathrm{Cl}$} & \multirow[b]{2}{*}{ AOR } & \multirow[b]{2}{*}{$95 \% \mathrm{Cl}$} & \multirow[b]{2}{*}{$\%$} & \multirow[b]{2}{*}{$95 \% \mathrm{Cl}$} & \multicolumn{2}{|l|}{$\boldsymbol{\beta}$} \\
\hline & & & & & & & Coeff. & $95 \% \mathrm{Cl}$ \\
\hline \multicolumn{9}{|l|}{ Gender } \\
\hline Male & 70.6 & (68.1 to 73.0$)$ & 1.0 & Referent & 35.8 & (34.5 to 37.2 ) & & Referent \\
\hline Female & 94.0 & (91.9 to 95.6$)$ & 4.4 & (2.9 to 6.7$)$ & 46.4 & (44.7 to 48.1$)$ & 6.4 & (3.9 to 8.8$)$ \\
\hline \multicolumn{9}{|l|}{ Age (years) } \\
\hline $12-17$ & 95.1 & (93.0 to 96.6$)$ & 9.0 & (5.7 to 14.2 ) & 46.0 & (44.3 to 47.7$)$ & 10.0 & (6.8 to 13.2$)$ \\
\hline $18-25$ & 88.7 & (87.2 to 90.1$)$ & 3.9 & (2.9 to 5.0 ) & 44.4 & ( 43.2 to 45.6$)$ & 8.7 & (5.9 to 11.5$)$ \\
\hline $26-34$ & 72.2 & (68.1 to 75.9$)$ & 1.2 & (0.8 to 1.6$)$ & 36.0 & (33.5 to 38.6 ) & 1.0 & $(-2.8$ to 4.8$)$ \\
\hline 35 or older & 63.2 & (58.5 to 67.6$)$ & 1.0 & Referent & 32.6 & (30.0 to 35.3 ) & & Referent \\
\hline \multicolumn{9}{|l|}{ Race/ethnicity } \\
\hline White & 70.0 & (67.4 to 72.5 ) & 1.0 & Referent & 36.3 & (34.8 to 37.8 ) & & Referent \\
\hline Black & 94.4 & (90.6 to 96.7 ) & 6.7 & (3.4 to 13.2 ) & 43.9 & (41.4 to 46.4 ) & 4.0 & (1.0 to 7.1 ) \\
\hline Hispanic & 74.4 & (66.6 to 80.9 ) & 1.0 & (0.6 to 1.5$)$ & 36.7 & (32.9 to 40.5 ) & -2.0 & $(-5.9$ to 1.9$)$ \\
\hline Other & 74.3 & (63.3 to 82.9 ) & 1.4 & (0.7 to 2.8 ) & 39.7 & (32.5 to 46.8 ) & 3.4 & $(-2.7$ to 9.5$)$ \\
\hline \multicolumn{9}{|l|}{ Cigarette uset } \\
\hline Yes & 84.7 & (82.3 to 86.8 ) & 2.5 & (1.9 to 3.2 ) & 42.4 & (41.0 to 43.9 ) & 7.0 & (4.5 to 9.5 ) \\
\hline No & 64.4 & (60.1 to 68.4 ) & 1.0 & Referent & 32.8 & (30.3 to 35.3 ) & & Referent \\
\hline \multicolumn{9}{|l|}{ Blunt uset } \\
\hline Yes & 94.5 & (93.0 to 95.6 ) & 2.8 & (1.8 to 4.3 ) & 49.0 & (47.5 to 50.5 ) & 6.4 & (4.1 to 8.6 ) \\
\hline No & 70.4 & (67.8 to 72.8 ) & 1.0 & Referent & 35.1 & (33.7 to 36.6 ) & & Referent \\
\hline \multicolumn{9}{|l|}{ Cigar uset } \\
\hline Less than 5 days & 70.3 & (67.9 to 72.7 ) & 1.0 & Referent & 34.9 & (33.6 to 36.2 ) & & Referent \\
\hline 5-29 days & 82.5 & (76.7 to 87.1 ) & 1.8 & (1.3 to 2.5 ) & 42.5 & (39.3 to 54.8 ) & 6.3 & (3.1 to 9.5 ) \\
\hline All 30 days & 90.8 & (83.9 to 95.0 ) & 6.4 & (3.2 to 13.1 ) & 47.9 & (44.0 to 51.7 ) & 13.7 & (9.6 to 17.7 ) \\
\hline Overall & 75.1 & (73.0 to 77.1 ) & & & 37.9 & (36.7 to 39.1 ) & & \\
\hline
\end{tabular}

flavoured and so an individual who expresses preference for a brand that offers even a very high proportion of flavoured products may actually smoke an unflavoured cigar product offered by that brand. Second, NSDUH collects data on 'usual brand' smoked in the past 30 days, and as such does not capture all brands and/or subtypes smoked. Third, the cigar market is extremely diverse and varies with regards to size (eg, filtered vs large cigar) and packaging (single stick vs pack of 20). As such, we decided on using dollar instead of unit share to calculate each brand's flavoured market share. We had also considered cigar stick shares, but that approach conflated the little cigar brands' market share. However, within brand there was little variation in flavoured market share across these three approaches. Fourth, dichotomising our outcome variable (brand makes flavoured cigars) may serve as a proxy for premium cigars since most of the inexpensive mass market, machine-made cigars are flavoured, whereas premium cigars are typically not flavoured. However, it should be noted that the findings from the logistic regression were robust and consistent with the linear regression that used a continuous measure as the outcome (ie, flavoured market share within brand). Fifth, data on cigar flavour are only as reliable as what can be captured by Nielsen on the product packaging. Lastly, Nielsen data were limited to convenience store sales only. While these data reflect a majority of national cigar sales, smokers who purchase cigars via other channels (eg, specialty shops, internet sites) may differ in their tobacco use profile (eg, occasional premium cigar use). Nonetheless, the cigar brands captured in Nielsen data largely reflect the brand preferences reported by youth and adults in the NSDUH data. Indeed, inexpensive mass market, machinemade cigars reflect the overwhelming majority of cigar sales, whereas premium cigars comprised only $2 \%$ of the total US cigar market in 2011.35

This study highlights recent shifts in the attributes of cigar products sold in US convenience stores, including growth in flavoured cigar sales. Brands that manufacture flavoured cigars tended to be more popular among youth and young adults than their older counterparts. Recognising the importance of preventing youth tobacco initiation, local jurisdictions in New York City, NY, Providence, RI, and Chicago, IL, have placed restrictions on the sale of flavoured products. ${ }^{36-38}$ As one of the strongest regulatory tools under its authority, the FDA can set federal tobacco product standards, such as reducing the addictiveness, toxicity or appeal for products, under its jurisdiction. Of note, the FDA has asserted its intention to deem all products meeting the statutory definition of a tobacco product, including cigars, under agency jurisdiction, ${ }^{39}$ and as of March 2014 this proposed regulation is in regulatory review at the Office of Management and Budget (OMB). Expanding the evidence base to inform regulatory actions to protect public health is critical for federal, state and local tobacco control efforts. As such, evaluations of the local flavour sales restrictions, complemented by additional studies examining the impacts of flavoured tobacco product use on individual-level tobacco use behaviours and tobacco use trajectories, would be valuable additional contributions to the knowledge base. Moreover, there is a need to 
expand existing surveillance systems to monitor tobacco product attributes as well as to collect more detailed information on individual-level tobacco product characteristics associated with use behaviours to expand the evidence base to support local and national tobacco control efforts.

\section{What this paper adds}

No study to date has examined use of and preference for flavoured cigars among both youth and adults. By linking nationally representative survey data with Universal Product Code scanner data to characterise respondents' preferred brands, we are able to identify groups that are more likely to report use of a brand that produce flavoured cigars. Such data can help to inform regulatory policies.

Contributors CDD conceptualised the study, oversaw all analyses, took primary responsibility for writing and is responsible for the overall content. DPG participated in data coding and analysis, and writing. BKA, CGC and KPC participated in data interpretation and writing. The views and opinions expressed in this paper are those of the authors only and do not necessarily represent the views, official policy or position of the US. Department of Health and Human Services or any of its affiliated institutions or agencies.

Funding This project has been funded in part with Federal funds from the National Institute on Drug Abuse, National Institutes of Health, and the Food and Drug Administration, Department of Health and Human Services, under contract no. HHSN271201100027C.

\section{Competing interests None.}

Ethics approval This study was a secondary data analysis of publicly available data and is considered non-human subjects research by the Rutgers Institutional Review Board.

Provenance and peer review Not commissioned; externally peer reviewed.

\section{REFERENCES}

1 U.S. Department of Treasury . The Alcohol and Tobacco Tax and Trade Bureau. Tobacco Statistics. 2012. http://www.ttb.gov/tobacco/tobacco_stats.html

2 U.S. Department of Agriculture. Tobacco outlook. Washington: U.S. Department of Agriculture, Economics Research Service, 2007. TBS-263.

3 National Cancer Institute. Cigars: health effects and trends. Bethesda, MD: U.S. Dept of Health and Human Services, Public Health Service. Smoking and Tobacco Control Monograph No. 9. NIH publication, 1998;98-4302.

4 Gilpin EA, Pierce JP. Cigar smoking in California: 1990-1996. Am J Prev Med 1999;16:195-201.

5 Hyland A, Cummings KM, Shopland DR, et al. Prevalence of cigar use in 22 North American communities: 1989 and 1993. Am J Public Health 1998;88:1086-9.

6 Nyman AL, Taylor TM, Biener L. Trends in cigar smoking and perceptions of health risks among Massachusetts adults. Tob Control 2002;11(Suppl 2):ii25-8.

7 Gilpin EA, Pierce JP. Patterns of cigar use in California in 1999. Am J Prev Med 2001:21:325-8.

8 Cullen J, Mowery P, Delnevo C, et al. Seven-year patterns in US cigar use epidemiology among young adults aged $18-25$ years: a focus on race/ethnicity and brand. Am J Public Health 2011;101:1955-62.

9 Delnevo CD, Bover-Manderski MT, Hrywna M. Cigar, marijuana, and blunt use among US adolescents: are we accurately estimating the prevalence of cigar smoking among youth? Prev Med 2011;52:475-6.

10 Delnevo CD, Foulds J, Hrywna M. Trading tobacco: are youths choosing cigars over cigarettes? Am J Public Health 2005;95:2123.

11 Jolly DH. Exploring the use of little cigars by students at a historically black university. Prev Chronic Dis 2008;5:A82.

12 SAMHSA. National survey on drug use and health. Rockville, Maryland: U.S. Department of Health and Human Services, Substance Abuse and Mental Health Services Administration producer, 2003. Ann Arbor, MI: Inter-university Consortium for Political and Social Research distributor.
13 SAMSHA. Substance abuse and mental health services administration. National survey on drug use and health. Rockville, Maryland: U.S. Department of Health and Human Services, Substance Abuse and Mental Health Services Administration producer, 2012. Ann Arbor, MI: Inter-university Consortium for Political and Social Research distributor.

14 Delnevo CD, Pevzner ES, Steinberg MB, et al. Cigar use in New Jersey among adolescents and adults. American J Public Health 2002;92:943-5.

15 U.S. Department of Health and Human Services. Preventing tobacco use among youth and young adult: a report of the surgeon general. Atlanta: U.S. Department of Health and Human Services, Centers for Disease Control and Prevention, National Center for Chronic Disease Prevention and Health Promotion, Office on Smoking and Health, 2012.

16 Delnevo CD. Smokers' choice: what explains the steady growth of cigar use in the U.S.? Public Health Rep 2006;121:116-19.

17 Delnevo CD, Hrywna M. "A whole 'nother smoke'" or a cigarette in disguise: how RJ Reynolds reframed the image of little cigars. American. J Public Health 2007:97:1368-75.

18 Ashare RL, Hawk LW Jr, Cummings KM, et al. Smoking expectancies for flavored and non-flavored cigarettes among college students. Addict Behav 2007;32:1252-61.

19 Carpenter CM, Wayne GF, Pauly JL, et al. New cigarette brands with flavors that appeal to youth: tobacco marketing strategies. Health Affair 2005;24:1601-10.

20 Connolly GN. Sweet and spicy flavours: new brands for minorities and youth. Tob Control 2004;13:211-12.

21 Cummings KM, Morley CP, Horan JK, et al. Marketing to America's youth: evidence from corporate documents. Tob Control 2002;11(Suppl 1):15-17.

22 Klein SM, Giovino GA, Barker DC, et al. Use of flavored cigarettes among older adolescent and adult smokers: United States, 2004--2005. Nicotine Tob Res 2008; 10:1209-14.

23 Manning KC, Kelly KJ, Comello ML. Flavoured cigarettes, sensation seeking and adolescents' perceptions of cigarette brands. Tob Control 2009;18:459-65.

24 Flavored Cigars-The Industry's "Mustang?" 1969. Tobacco Reporter. http://legacy. library.ucsf.edu/tid/jog84e00/pdf

25 Aulbach P. Brown and Williamson. New and unique flavors. 1969. http://legacy. library.ucsf.edu/tid/vqp60f00/pdf

26 Riell H. (2012). Maintaining strong cigar sales. Convenience Store Decisions, Retrieved from http://www.csdecisions.com/2012/08/21/maintaining-strongcigar-sales/

27 Energy around cigars puffs up.2013. Convenience Store News, Retrieved from. http://www.csnews.com/article-energy_around_cigars_puffs_up-5464.html

28 King BA, Dube SR, Tynan MA. Flavored cigar smoking among U.S. adults: findings from the 2009-2010 National Adult Tobacco Survey. Nicotine Tob Res2013;15:608-14.

29 Villanti AC, Richardson A, Vallone DM, et al. Flavored tobacco product use among U.S. young adults. Am J Prev Med 2013;44:388-91.

30 King BA, Tynan MA, Dube SR, et al. Flavored-little-cigar and flavored-cigarette use among U.S. middle and high school students. J Adolesc Health 2014;54:40-6.

31 Delnevo CD, Wackowski OA, Giovenco DP, et al. Examining market trends in the United States smokeless tobacco use: 2005-2011. Tob Control 2014;23:107-12

32 Tobacco Products Scientific Advisory Committee. Menthol cigarettes and public health: review of the scientific evidence and recommendations. Rockville, MD: Center for Tobacco Products, Food and Drug Administration, 2011. http://www.fda. gov/downloads/AdvisoryCommittees/CommitteesMeetingMaterials/Tobacco ProductsScientificAdvisoryCommittee/UCM269697.pdf

33 Sifaneck SJ, Johnson BD, Dunlap E. Cigars-for-blunts: choice of tobacco products by blunt smokers. J Ethn Subst Abuse 2005;4:23-42.

34 Crawford GE. Flavoured tobacco products with marijuana names. Tob Control 2007;16:70.

35 Maxwell JC. The maxwell report: the cigar industry in 2011. Richmond, VA, 2012.

36 Flavored tobacco product sale. Official website of the city of New York. 2009. http://www1.nyc.gov/nyc-resources/service/2919/flavored-tobacco-product-sale/

37 Providence tobacco laws go into effect January 3. Official website of the city of Providence, Rhode Island, 2012. https://www.providenceri.com/healthy-communities/ providence-tobacco-laws-go-into-effect-january-3

38 City Council approves ordinance to regulate e-cigarettes as tobacco products. The city of Chicago's official site, 2014. http://www.cityofchicago.org/city/en/depts/cdph/ provdrs/boh/news/2014/jan/city-council-approves-ordinance-to-regulate-e-cigarettesas-toba.html

39 About the Center for Tobacco Products. U.S. Food and Drug Administration, 2014. http://www.fda.gov/AboutFDA/CentersOffices/OfficeofMedicalProductsandTobacco/ AbouttheCenterforTobaccoProducts/default.htm 